\title{
BLICKDIAGNOSE
}

\section{Jugularvenenthrombose Portsystem nicht optimal plaziert}

Nach einer Darmteilresektion wegen eines Kolonkarzinoms wurde bei dem 80-Jährigen für die anschließende Chemotherapie rechts ein infraklavikulärer Port implantiert. Eine lokale strangförmige Verhärtung über dem Schlüsselbein störte den Mann nicht. Im Routinelabor fiel drei Monate später ein erhöhter D-Dimerwert von 3,8 $\mathrm{mg} \%$ auf und war Anlass, nach einem thrombotischen Geschehen zu fahnden.

— Die Inspektion der oberen Throraxapertur zeigte einen derben Strang, der sich vom Port zum lateralen Hals erstreckte. Duplexsonografisch ließ sich darin der Silikonschlauch des Ports bis zur V. jugularis externa verfolgen. Unmittelbar distal der Einmündung kam in der V. jugularis interna ein bis zu $1 \mathrm{~cm}$ breiter wandständiger Thrombus zur Darstellung.

Jugularvenenthrombosen sind bei zervikalen malignen Erkrankungen, zentralen Venenkathetern und gelegentlich auch Drogenabhängigen keine Seltenheit. Thromboembolien, Infektionen oder appositionelles intrakranielles Wachstum stellen potenzielle Gefahren dar. Eine seltene Komplikation ist das Lemierre-Syndrom, die postanginöse bakteriell infizierte Jugularvenenthrombose mit septischer Streuung.

Im vorliegenden Fall wurde das distale Ende des Silikonschlauchs nicht optimal platziert. Normalerweise sollte es in der zentralen V. jugularis interna, V. subclavia oder V. cava superior liegen. Therapeutisch erfolgten eine rasche Entfernung des Portsystems und passagere Behandlung mit niedermolekularem Heparin.

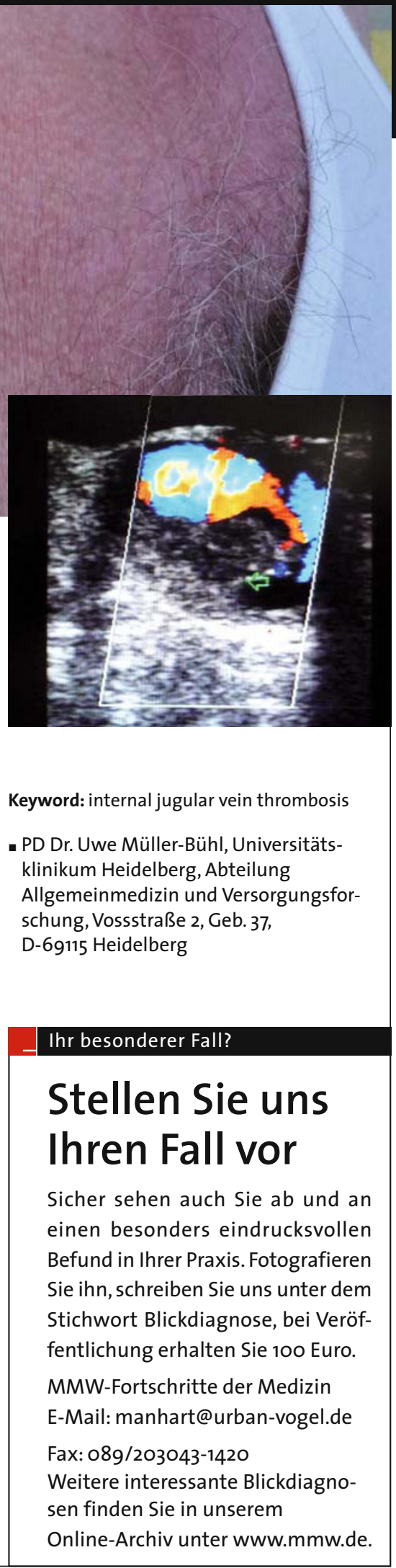

